\title{
Seawater ageing of low styrene emission resins for marine composites: Mechanical behaviour and nano-indentation studies
}

\author{
Romain Maurin ${ }^{a}$, Yves Perrot ${ }^{b}$, Alain Bourmaud ${ }^{a}$, Peter Davies $^{c, ~}{ }^{*}$ and Christophe Baley ${ }^{a}$
}

\footnotetext{
a Laboratoire L2PIC, Université de Bretagne Sud, 56321 Lorient, Cedex, France

${ }^{b}$ Société Nautique Conseil Développement, Technopole Brest Iroise, 29200 Brest, France

${ }^{c}$ Materials and Structures Group, IFREMER Brest Centre, 29280 Plouzané, France
}

*: Corresponding author : P. Davies, email address : Tel.: +33 2 98224777; fax: +33 2 98224535, email address : Peter.Davies@ifremer.fr romain.mourin@univ-ubs.fr, alain.bourmaud@univ-ubs.fr, christophe.baley@univ-ubs.fr, yves.perrot@yahoo.fr

\begin{abstract}
:
Polyester resins are widely employed for pleasure boat construction. In order to satisfy new environmental legislation on styrene emissions resin suppliers have proposed modified formulations, but these show lower failure strains under tensile loading. This paper examines the influence of wet ageing on mechanical properties of low styrene polyester, together with standard polyester and vinyl ester resins, and their glass reinforced composites. Results are presented from accelerated ageing in natural sea water for nine months, at temperatures of 20,40 and $60{ }^{\circ} \mathrm{C}$. Nano-indentation was used to study local changes in the resin after ageing. The diffusion kinetics of the low styrene emission resins and their composites are similar to those for standard polyester resins. The low styrene resins appear to lose strength more slowly than the standard resins but after nine months in seawater at $40^{\circ} \mathrm{C}$ similar property losses are noted.
\end{abstract}

Keywords: A. Polymer-matrix composites (PMCs); B. Environmental degradation; D. Mechanical testing 


\section{Introduction}

Polyester resins have been employed for pleasure boat construction since the 1950's. However, in recent years concerns over volatile emissions during fabrication have resulted in new environmental legislation on styrene emissions and resin suppliers have proposed new formulations. These are of three types:

Low styrene content. In this case the molecular weight of the pre-polymer is reduced to keep viscosity low.

Low styrene emission resins. Here additives are included which block styrene emission during fabrication by creating a surface film.

Mixed resins, combining low styrene content and emission.

The mechanical properties of glass reinforced polyester laminates depend on a number of factors. The fibre orientation and content are critical but the matrix also plays an important role in maintaining the geometry, providing off-axis strength and protecting the fibres from the environment. The fibre/matrix interface also contributes to these functions. In a previous study, Baley et al [1] have described the influence of cure conditions (time and temperature) on the mechanical properties of unreinforced polyester resins. In that study significant differences were noted between the mechanical properties of standard polyester resins and those limiting styrene emissions. The latter showed low tensile failure strains, which resulted in early damage in glass mat reinforced composites. For similar resin formulations Perrot et al [2] examined delamination resistance and impact behaviour. The low styrene resins showed lower resistance to delamination propagation under mode I loading (for unidirectional composites), and larger delaminated areas for a given impact energy (for rovimat reinforced composites). These results show the importance of the matrix in the events leading to failure of glass/polyester composites. The ductility of the matrix resin is a critical parameter which conditions the appearance and progression of damage. The aim of the present paper is to complete the study of the behaviour of low styrene resins by presenting a study of their ageing behaviour. Many published studies provide data on aged glass reinforced composites, e.g. [3-6], but very few results allow a comparison to be made between the ageing of standard and low styrene materials. This is the main aim of the work described below. Standard resins and their composites have been subjected to immersion in sea water for 9 months. Mass gain due to diffusion and the change in mechanical properties have been studied using conventional mechanical tests. Nano-indentation is used on resin samples in order to examine whether this technique can provide additional information on the mechanisms involved in aging.

\section{Materials and experimental methods}

\subsection{Materials studied}

Four commercial resins have been studied, supplied by the three main suppliers to the French boatbuilding industry: a standard orthophthalic polyester (SO), a low styrene content DCPD (dicyclopentadiene) orthophthalic polyester (LS), a low styrene emission orthophthalic polyester (LES) and a vinylester (SV). The two low styrene polyesters (LS, and LES) are commonly used in pleasure boat construction. Table 1 indicates their styrene contents given by suppliers and tensile properties measured in a previous study [1]. The failure strains of the low styrene resins are quite low, it should be remembered that glass fibres fail at strains around $2.8 \%$ 
All the materials, resins and composites, used in this study were mixed in a laboratory at room temperature $\left(20 \pm 2^{\circ} \mathrm{C}\right)$ with $1.5 \%$ by weight of methyl ethyl ketone peroxide (MEKP). The cure cycle was 24 hours at room temperature followed by 16 hours at $40^{\circ} \mathrm{C}$, which enables a cure state to be reached which is close to that encountered in industrial parts [1]. Unreinforced resin panels $4 \mathrm{~mm}$ thick were obtained by casting and were then machined to produce dog-bone specimens. Composites were made by contact moulding and roller compaction. Two types of glass fibre reinforcement, with compatible sizing for the resins studied here, were combined; $300 \mathrm{~g} / \mathrm{m}^{2}$ mats and balanced $500 \mathrm{~g} / \mathrm{m}^{2}$ woven taffetas. Samples were seven layers thick, alternating four mat plies with three of taffeta. This sequence was chosen as it is a typical lay-up. Thinner specimens would allow faster aging, but it is not possible to obtain very thin specimens which are representative of the real material used in these applications. The fibre content was measured by burn-off ( 1 hour at $650^{\circ} \mathrm{C}$ following NF T 57 102) and calculation to be between 20 and $22 \%$ by volume.

\subsection{Aging conditions}

Directly after curing both resins and composites were placed in continuously circulating natural sea water containers for up to 9 months. The seawater is pumped directly from the Brest Estuary and is available on tap at the IFREMER centre. The only filtering is to remove sediment particles. The resins were aged at $40^{\circ} \mathrm{C}$, the composites were immersed at 20,40 and $60^{\circ} \mathrm{C}$. Mass gain was followed by periodic weighing on a Sartorius LA $310 \mathrm{~S}$ balance (precision $0.1 \mathrm{mg}$ ). Samples were removed from the aging containers and wiped with paper towels before weighing to dry the surfaces. The mass $\mathrm{M}$ of each sample at time $\mathrm{t}$ is expressed as a percentage as :

$$
M=\frac{M_{t}-M_{0}}{M_{0}} * 100
$$

\subsection{Mechanical tests}

An Instron 4302 test machine was used to perform tensile and flexure tests on specimens at a loading rate of $2 \mathrm{~mm} / \mathrm{min}$. Unreinforced resins were tested in the form of dog-bone specimens according to the ISO standard 5276. An Instron extensometer 2620-602 was used to measure strains with a gauge length of $25 \mathrm{~mm}$. Three point flexure was used to measure properties of parallel composite specimens following French standard NF T 57105 (distance between supports 16 times the specimen thickness). All samples were tested wet on removal from the aging containers, after a delay of 30 minutes to allow the specimen temperature to reach room temperature. At least four tensile and flexure specimens were tested for each aging condition. Dynamic mechanical analysis (DMA) was also performed in three point flexure on resins after 9 months in water at $40^{\circ} \mathrm{C}$, using a TA Instruments DMA 2980. The standard ISO 6721 procedure was applied $\left(1 \mathrm{~Hz}, 3^{\circ} \mathrm{C} / \mathrm{min}\right.$ distance between supports $50 \mathrm{~mm}$ ). The glass transition temperatures $(\mathrm{Tg})$ quoted here correspond to the change in slope of the plots of storage modulus versus temperature.

\subsection{Nanoindentation}

Tests were performed on resin samples using an MTS XP machine with a Berkovitch indenter. The tip displacement is controlled during indentation with a loading frequency of $70 \mathrm{~Hz}$ (dynamic / continuous stiffness measurement method unless noted otherwise). Figure 1 shows the form of the indents. 
The loads are measured during indentation and unloading. Figure 2 shows a typical force-displacement plot $(P=f(h))$ for a polyester resin.

Contact pressure is determined from the plastic penetration depth. The imprint area, $A$, is calculated as [7]:

$$
A=3 \sqrt{3} h_{p}^{2} \tan ^{2}(\Theta)
$$

with $\theta=65.3^{\circ}$ for the Berkovitch tip and this simplifies to $A=24.5 h_{p}{ }^{2}$. From the contact depth $\left(h_{p}\right)$, the maximum depth $\left(h_{\max }\right)$ and the maximum force $\left(P_{\max }\right)$, a contact stiffness $(\mathrm{S}=\mathrm{d} P / \mathrm{d} h)$ is calculated. For this tip the geometrical factor $\varepsilon=0.75$.

$$
h_{p}=h_{\max }-\varepsilon \frac{P_{\max }}{S}
$$

The contact stiffness allows a reduced modulus $\left(E_{r}\right)$ to be determined as a function of the geometry of the tip using the method proposed by Oliver and Pharr [8]. $A$ is the contact radius, and $\beta$ is a geometrical constant, $\beta=1.034$ for the Berkovitch tip.

$$
E_{r}=\frac{S \sqrt{\pi}}{2 \beta \sqrt{A}}
$$

The reduced modulus does not take into account the strain in the diamond tip. In order to obtain the sample modulus this component must be removed (using indenter modulus $\mathrm{E}_{\mathrm{i}}=1140 \mathrm{GPa}$ and indenter Poisson's ratio $v_{\mathrm{i}}=0.07$ ) [6].

$$
E=\frac{\left(1-v^{2}\right)}{\frac{1}{E_{r}}-\frac{\left(1-v_{i}{ }^{2}\right)}{E_{i}}}
$$

An alternative analysis was proposed by Loubet [9]. The contact stiffness is still calculated using Sneddon's equation (4), but Loubet's method takes into account the imperfect shape of the indentation.

$$
S=B\left(h_{p}+h_{1}\right)
$$

$h_{p}$ is the plastic depth calculated by equation 3 with $\varepsilon=1$ and $h_{1}$ is the apparent tip defect. $h_{1}$ and $B$ are determined experimentally.

Loubet's method adds $h_{1}$ in the imprint formula as well.

$$
\begin{gathered}
h_{c}=\alpha\left(h_{p}+h_{1}\right) \text { where } \alpha=1.2 \\
A=\beta * h_{c}^{2}
\end{gathered}
$$

Using equations 4, 6 and 8 we can calculate the reduced modulus.

$$
E_{r}=\frac{\sqrt{\pi B}}{2 \alpha \sqrt{\beta}}
$$


Additional information from these tests is a value of the tan $\delta$, this is defined as E'/E' where E" is the out-of phase (loss) modulus and E' the in-phase (storage) modulus component.

Nanoindentation was performed on the aged resin tensile specimens described above. Before each series of tests a calibration indentation was performed according to the standard test method described in [7]. Each test then consisted of placing the tip in contact with the sample and loading. Indentation depth was $2000 \mathrm{~nm}$ and the rate of loading and unloading was $0.05 \mathrm{~s}^{-1}$. This depth was chosen following preliminary studies using different depths, which indicated larger variability of modulus values for small depths. The load was maintained for 60s. Then the sample was unloaded at the same rate to $10 \%$ of the maximum load and the thermal drift of the test was calculated. First, in order to measure surface modulus, a series of measurements was made directly after aging, at different points (50 measurements) to obtain a representative measurement of elastic modulus. In this case the as-aged surface was indented. A second series of measurements was made subsequently, this time through the specimen thickness in order to examine stiffness profiles. In this case specimens had been left for at least 9 months in air before indentation, in order to allow water desorption. These samples were cut and polished with diamond paste to $3 \mu \mathrm{m}$. Through thickness measurements were made in two directions, defined as Transverse and Longitudinal, at mid-length of the tensile specimens:

- Transverse indentations along lines of 100 equi-distant indentations through the sample thickness, Figure 3a.

- Longitudinal measurements were made along three lines of 50 indentations each along the specimen mid-thickness (Figure 3b). 50 indentations were made in each of the edge zones and 50 in the central : in this case the spacing between central zone indentations is double that of the edge zones.

In a preliminary study both analyses, equations (4) and (9), were applied to results from tests on the surface of a standard polyester sample at different frequencies, Table 2. No significant influence of analysis method on the modulus was noted, so only the former calculation method was retained to analyze data from through-thickness tests.

\section{Results and discussion}

\subsection{Mass gain of resins and composites}

Figure 4 shows how the masses of resins and composites change with square root of time during immersion at $40^{\circ} \mathrm{C}$. The three polyesters show similar behaviour, close to Fickian though a stable saturation plateau is not reached. The vinylester shows a different behaviour with much lower mass gain. The reinforced polyester materials are again similar but show continuous mass gains and no sign of a plateau. This type of behaviour is frequently observed for these materials [4,5]. Although the standard and low styrene polyesters have different chemical compositions they appear to absorb similar amounts of water. However it should be noted that mass gain depends on many factors, including the degree of cross-linking, interfaces and defects such as voids.

\subsection{Tensile properties of resins after aging}

Figure 5 presents typical load-displacement plots and Figure 6 shows tensile properties of the four resins before and after aging for 9 months in seawater at $40^{\circ} \mathrm{C}$. The trends are similar for all four materials, an increase in modulus (up to $16 \%$ for the polyesters 
and nearly $30 \%$ for the vinyl ester) and a large drop in failure strain (35\% loss for the LES polyester, which is the most brittle initially, and between 50 and $60 \%$ for the other materials). The post-cure applied here $\left(16 \mathrm{~h}\right.$ at $\left.40^{\circ} \mathrm{C}\right)$ is used to obtain materials equivalent to industrial components left for 3 months at $20^{\circ} \mathrm{C}$ without post-cure but does not result in complete cure [1]. Complete post-curing of samples would be possible, and might simplify interpretation of the results, but it is never found in service so has little practical significance. The thermal energy of seawater heated to $40^{\circ} \mathrm{C}$ enables cure to continue as clearly indicated by DMA results in Table 3 . Values of $\mathrm{Tg}$ after 9 months at $40^{\circ} \mathrm{C}$ are 15 to $20^{\circ} \mathrm{C}$ higher than initial values. Similar increases in $\mathrm{T}_{\mathrm{g}}$ and storage modulus are noted for the three polyesters. This evolution of cure makes the interpretation of the results more difficult, but the drop in strain to failure is very large and cannot be explained solely by higher cross-linking [1]. There is also a degradation of the resins. The low styrene resins lose proportionally a little less of their ductility after aging but as they are very brittle initially they are even more brittle after aging. It should also be noted that in service boat structures made with these resins will continue to cure, and temperatures of $40^{\circ} \mathrm{C}$ are not extreme. There will be a drop in $\mathrm{Tg}$ as water enters the material, typically $10^{\circ} \mathrm{C}$ per percent of water, but for an aging temperature of $40^{\circ} \mathrm{C}$ the material Tg will still be above the bath temperature.

\subsection{Nanoindentation}

The tests described above are traditionally used to study this type of material and provide a global indication of properties. In order to examine how properties evolve on a local level nanoindentation was used on three of the resins (SO, LS and SV). This is a very powerful technique but requires certain precautions to validate the procedures. A large number of preliminary tests, such as those described in Table 2, allowed the test conditions to be defined. Modulus was independent of frequency over the range studied so $70 \mathrm{~Hz}$ was used for indentation through the sample thickness. At this frequency there is little influence of parasite frequencies. Nanoindentation is sensitive to surface modifications and moisture, but due to the long drying period any changes noted are caused by irreversible changes in the materials.

Figure 7 shows the profiles of E' and tangent $\delta$ for the standard polyester. The first observation, Figure $7 \mathrm{a}$, is that the modulus is not uniform through the specimen thickness. This is the case for all aging periods. The modulus is lower at the specimen edges and reaches a maximum at the specimen centre. Tangent $\delta$ shows the opposite trend, Figure $7 \mathrm{~b}$, being highest at the edges and lowest in the centre. This is noted for all three resins but the kinetics of the changes during aging vary with resin type. The vinyl ester (not shown) shows similar behaviour. The properties of the central region hardly evolve during aging, while the properties of the faces (in contact with warm water) increase to reach those of the centre. This suggests that the dominant mechanism is a post-cure. For the first 6 months the modulus at the centre increases with no change to the outer region, while the tangent $\delta$ decreases. After 6 months the central modulus stabilizes ( $E^{\prime}$ and E'). Between 6 and 9 months the properties of the outer regions change until uniform behaviour is observed. This suggests that for these two resins the aging effects are also minor compared to the post-curing effects (increase in E' and decrease in tan $\delta$ ). The reasons for the evolution in properties from the centre to the outer surfaces are complex. Exothermic reactions may result in higher degree of curing at the centre initially, particularly as fabrication involves casting into a steel mould, which may result in temperature gradients from the surface to the centre. The subsequent contact with water at $40^{\circ} \mathrm{C}$ allows cure to continue, though chemical 
effects such as leaching out of small molecular weight species at the surface may also affect the final resin state.

The response of the low styrene content resin to aging is rather different, Figure 8 . In this case the initial properties (E', E' and Tan $\delta$ ) appear quite uniform. During aging the modulus decreases significantly at the edges, while the tangent $\delta$ starts to increase. This suggests that degradation related to water ingress is occurring. The main mechanisms which are observed during aging of polyesters are plasticization, which is generally reversible when water is removed, differential swelling, residual stress relaxation, and hydrolysis. The nanoindentation results presented here do not allow us to separate these phenomena, but they do clearly illustrate the heterogeneous nature of both the materials and the changes during aging. To complete this section a series of longitudinal indentations was performed on samples aged for nine months, to check that the changes observed were not confined to one section. Figure 9 shows an example of the results from transverse and longitudinal indentations, (note the expanded y-axis scale), and very similar profiles (e.g. similar centre modulus values around 4.5 GPa and edge values around 3.5 GPa for the LS material) are noted for all three materials.

It is important to note that nanoindentation and tensile tests do not measure exactly the same properties. Generally nanoindentation modulus values are higher than results from standard tensile tests. This is the case here, the former are from 10 to $50 \%$ higher than the latter as shown in Figure 10, which shows average values across the indented section. Several reasons have been invoked to explain this:

The type of loading is compressive in nanoindentation, not tensile,

The test frequencies are quite different $(70 \mathrm{~Hz}$ for nanoindentation, compared to a much lower frequency in the quasi-static tensile test),

Hydrostatic pressure is generated below the Berkovitch indenter [10],

Surface effects, the initial part of the force-depth curve is affected by surface roughness, local oxidation [11] and other surface phenomena.

While the trends in tensile test modulus and nanoindentation modulus appear similar for the standard materials SV and SO, which have mainly evolved due to post-curing, the low styrene resin results are contradictory. This may be related to the fact that while the tensile tests were performed directly after aging, on specimens containing water, nanoindentation was performed on specimens which had dried slowly over a period of several months. Relaxation and even hydrolysis may occur during the drying period. Rapid desorption by increasing temperature could have been used to minimize the influence of water during that period but this introduces other changes.

\subsection{Flexural properties of composites after aging}

The influence of aging on composite properties was evaluated using three point flexure tests. Figure 11 shows typical load-displacement plots. This type of loading was selected as in the recent ISO standard for boat hull scantlings (ISO 12215 part 5) flexural properties rather than tensile are specified. Figure 12 shows how flexural modulus and failure stress of the fibre reinforced materials have changed after aging for 9 months at 20,40 and $60^{\circ} \mathrm{C}$. The modulus is reasonably stable, changes between $11 \%$ and $+17 \%$, are within scatter for this type of material [3]. A small drop is observed for the highest temperature. Failure stresses change significantly however, although the results from these tests do not show a strong influence of the type of resin. At $20^{\circ} \mathrm{C}$ the reductions are between $12 \%$ and $22 \%$ of the initial value. At $40^{\circ} \mathrm{C}$, the drop is between $25 \%$ and $30 \%$. Aging at $60^{\circ} \mathrm{C}$ leads to reductions between $47 \%$ and $60 \%$. It should be emphasised that flexural testing is very severe for aged specimens as the 
outer layers are those in contact with water and hence the most degraded, and it is these which are most highly loaded in this test. Testing of specimens without gel-coat and fully immersed also adds to the severity of these aging results compared to service conditions.

Figure 13 shows how failure stresses of the SO material, normalised with respect to initial unaged values, evolve with time. Photographs of the specimen surfaces taken at different times are also shown. The behaviour after aging at $60^{\circ} \mathrm{C}$ is quite different to that at the lower temperatures, there is no incubation time before a drop in strength. At 20 and $40^{\circ} \mathrm{C}$, there is a stable behaviour between 0 and 1000 hours, then the failure stress starts to drop. At $60^{\circ} \mathrm{C}$ degradation occurs rapidly from the start and the external mat layers become visible as white lines after 1500 hours immersion. 500 hours immersion at $60^{\circ} \mathrm{C}$ results in the same strength loss as 9 months at $20^{\circ} \mathrm{C}$. To a first approximation testing of the standard polyester SO at $60^{\circ} \mathrm{C}$ results in an acceleration of the aging mechanisms of around 15 times compared to the test at $20^{\circ} \mathrm{C}$. Figure 14 shows similar plots for the two other resins. Again there appears to be an incubation period before properties start to drop, this may be the time necessary for sufficient moisture to diffuse to the first layer of mat reinforcement. It is interesting to note that the rate of loss in strength at $60^{\circ} \mathrm{C}$ is more rapid for the vinylester than the low styrene resin. The latter decreases gradually with time, this may reflect the higher interfacial strength noted for this system in previous work [2], but overall the final values after 9 months at $60^{\circ} \mathrm{C}$ are similar for the three materials. It is also important to note that the large drops in resin tensile failure strain after 9 months at $40^{\circ} \mathrm{C}$ (Figure 6) are not reflected in similar drops in flexural strength of the composites $(20-30 \%$ for similar conditions). This underlines the importance of using appropriate tests in resin screening. However, the use of a more brittle matrix will result in the earlier appearance of micro-cracking in service, which will also favour water entry, and this effect has not been studied here. Tests of residual strength after aging of samples which have been pre-loaded to different strain levels are needed to quantify this.

\section{Conclusion}

Glass fibre reinforced polyesters are widely used in boat-building, and low styrene resins satisfying environmental regulations are increasingly replacing standard polyesters, both for contact moulding and infusion. In this study resin properties and the influence of aging in seawater have been examined at both the macroscopic and microscopic scale. This has shown that the macroscopic behaviour of low styrene resins is very similar to that of standard orthophthalic polyesters (same mass gain and property evolution). However, brittle initially, the low styrene grades are even more brittle after aging. Nanoindentation has revealed the heterogeneity of these materials and provides additional information on the complex changes which occur when postcuring and degradation occur simultaneously. Further testing of the ageing of composites using this technique is underway, but this requires great care due to local variability.

When these resins are employed in composites similar initial flexural properties are obtained for all four resins. After aging the changes in properties are similar for all the materials, but the rate of strength loss varies. The low styrene resins appear to lose strength more slowly than the standard resins but after 9 months similar losses are noted. It is tempting to suggest that changing from a standard polyester to a low styrene resin does not affect the aging behaviour of these marine composites, but further studies to examine coupling between damage and water ingress, and to quantify changes in damage tolerance are necessary before concluding. 


\section{Acknowledgements}

The authors acknowledge the contributions of resin suppliers, and support from the FIN, the Bretagne Region, the Conseil Général 56 and Eurolarge.

\section{References}

1. Baley C., Perrot Y., Davies P., Bormaud A., Grohens Y. Mechanical properties of composites based on low styrene emission polyester resins for marine application, Appl. Compos. Mater., 2006, 13, 1-22.

2. Perrot Y., Baley C., Grohens Y., Davies P., Damage resistance of composites based on glass fibre reinforced low styrene emissions resins for marine applications, Appl. Compos. Mater. 2007, 14, 67-87.

3. Springer GS, editor, Environmental effects on composite materials, Vol.1 (1981), Vol 2 (1984), Technomic publishers.

4. Geller E.P., Turley D.M., Seawater immersion ageing of glass-fibre reinforced polymer laminates for marine applications, Composites Part A 1999, 30, 1259-1265.

5. Davies P., Mazéas F., Casari P., Sea water ageing of glass reinforced composites: shear behaviour and damage modelling, J. of Comp. Materials, 2001, 35, 1343-1372.

6. Pritchard G, Reinforced Plastics Durability, Woodhead 1999.

7. Fischer-Cripps C., Nanoindentation, Springer 2002.

8. Oliver WC, Pharr GM, An improved technique for determining hardness and elasticmodulus using load and displacement sensing indentation experiments, J Mater Res, 1992, 7, 1564-1583.

9. Hochstetter G., Jimenez A., Loubet J. L. Strain-rate effects on hardness of glassy polymers in nanoscale range. Comparison between quasi static and continuous stiffness measurements, J. Macromol. Sci., Phys. B38 (5\&6), 1999, p 681-692

10. Briscoe B. J., Sebastian K. S.. The elastoplastic response of poly(methyl methacrylate) to indentation. Proceedings of the Royal Society of London 1996,452.

11. Hu Y., Shen L., Yang H., Wang M., Liu T., Liang T., Zhang J.. Nanoindentation studies on Nylon 11/clay nanocomposites. Polym. Test. 2006 25,4, 492. 


\section{Figures}

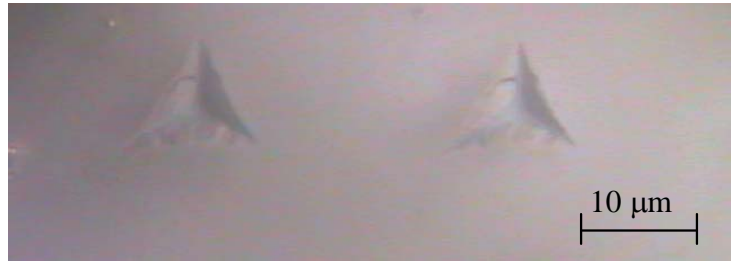

Figure 1 : Example of indent on resin surface.

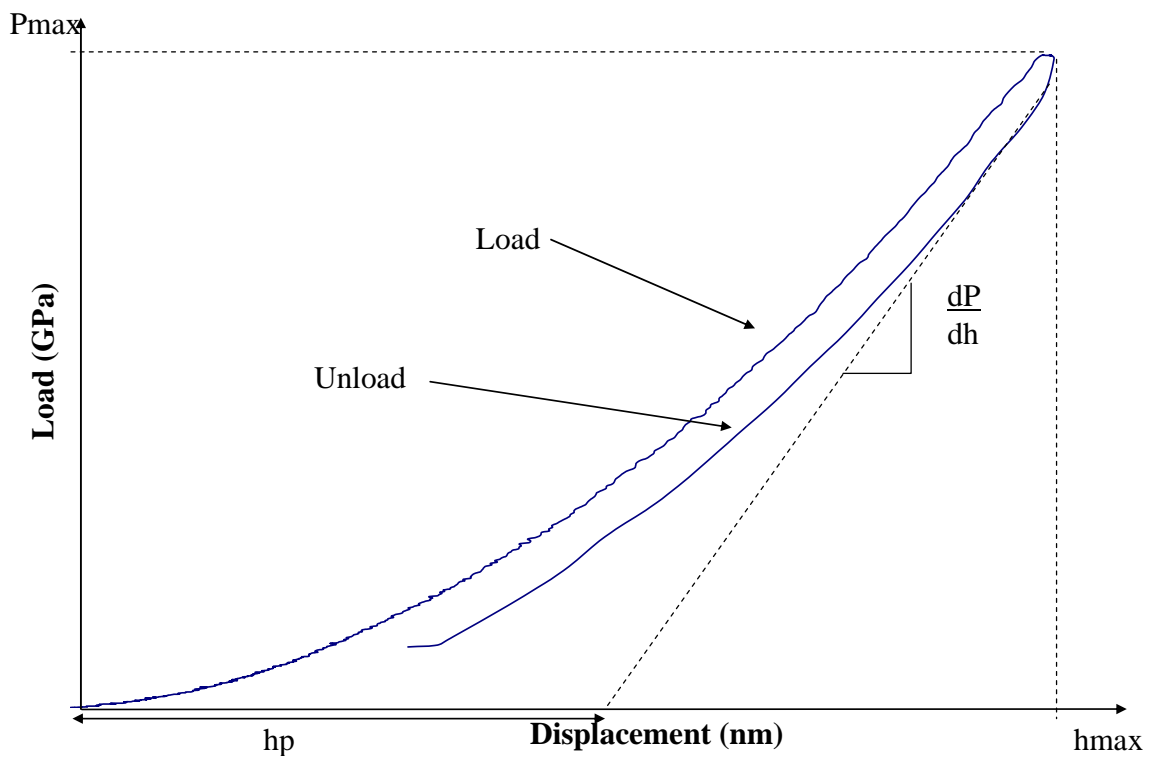

Figure 2: Example of force-displacement recording from nano-indentation test on polyester resin 

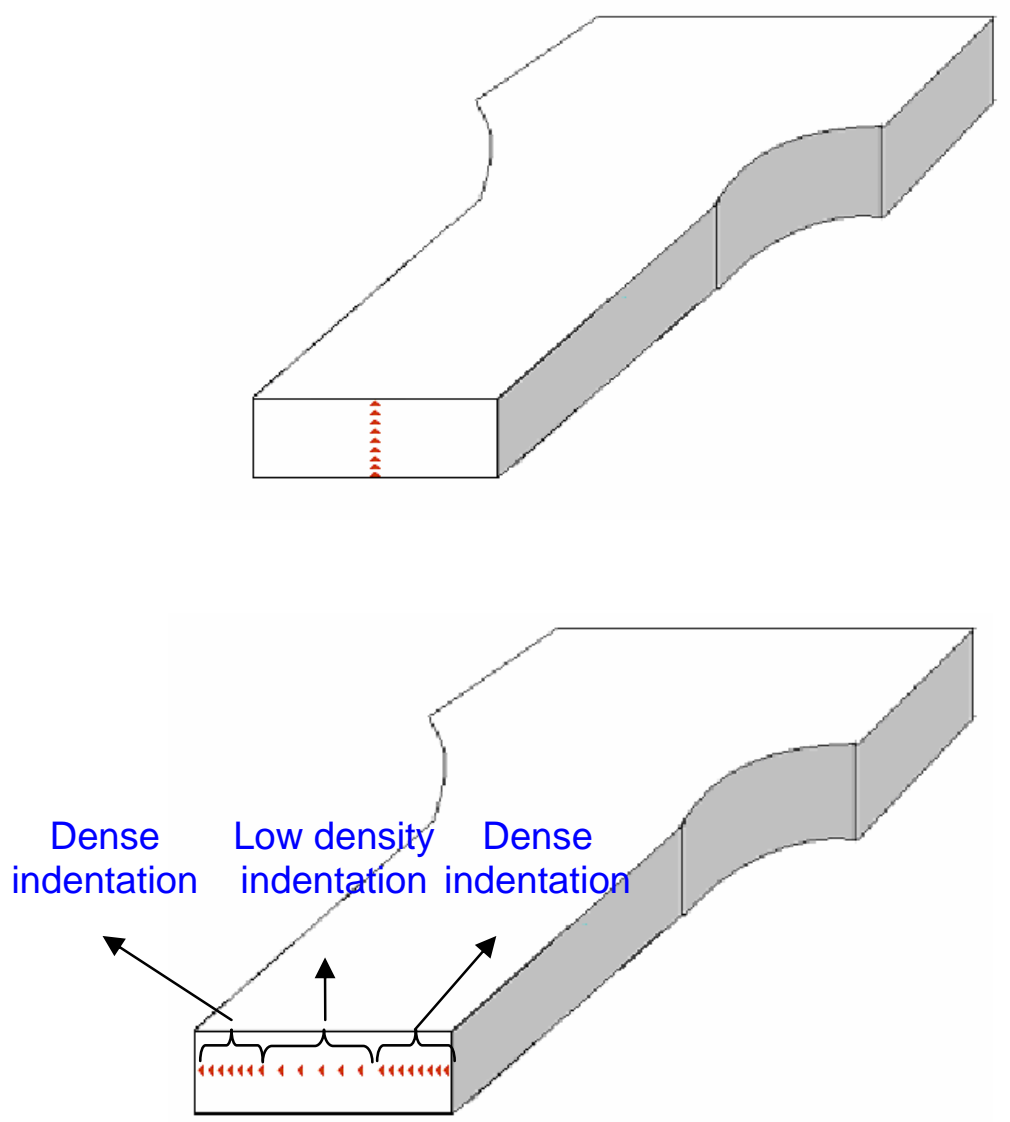

Figure 3. Position of nano-indentations, a) transverse, b) longitudinal. Red triangles indicate indentation positions. 

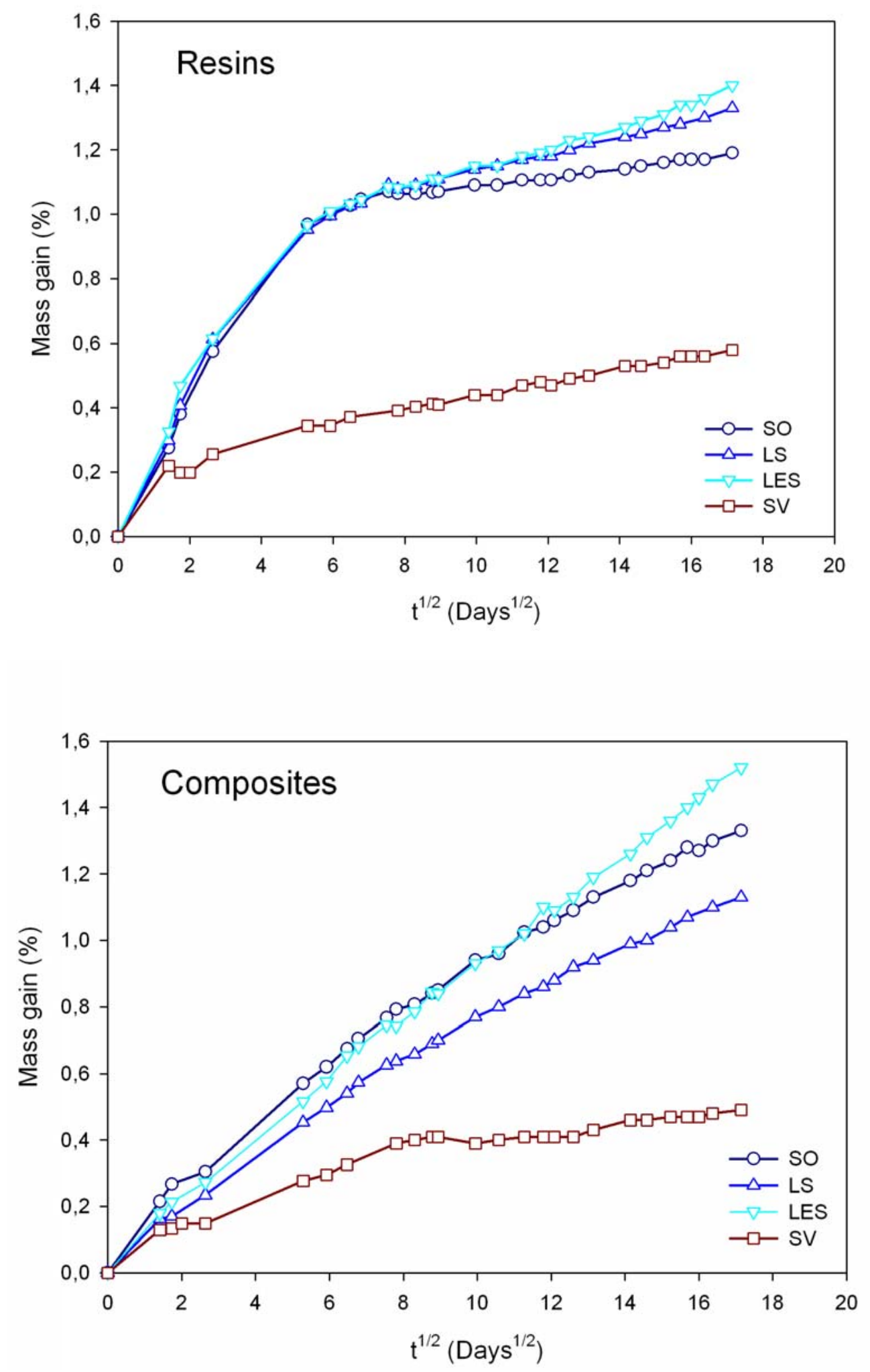

Figure 4: Resins and composites mass gains in sea water at $40^{\circ} \mathrm{C}$ 


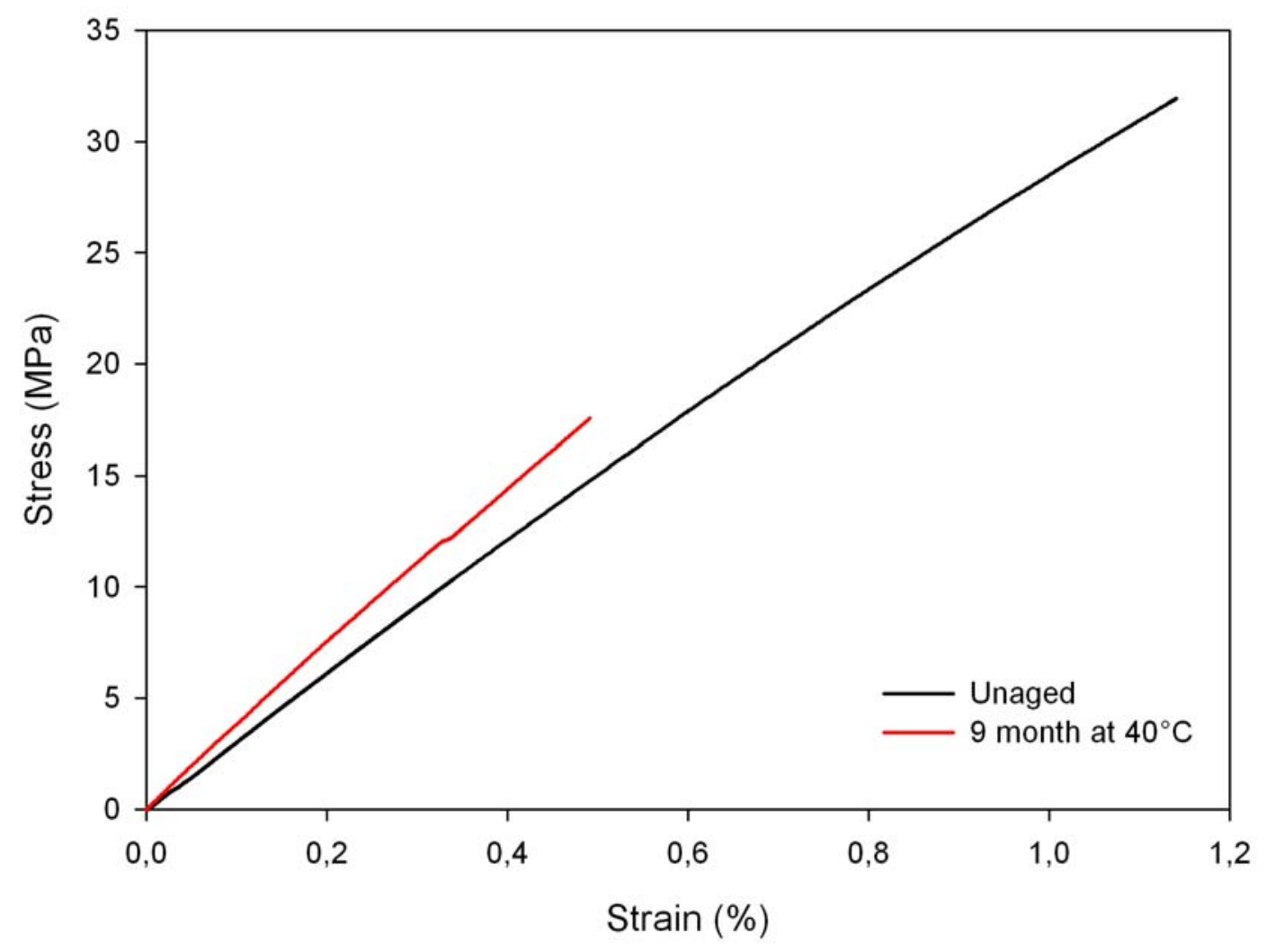

Figure 5 : Typical tensile test stress-strain plots, LS resin 

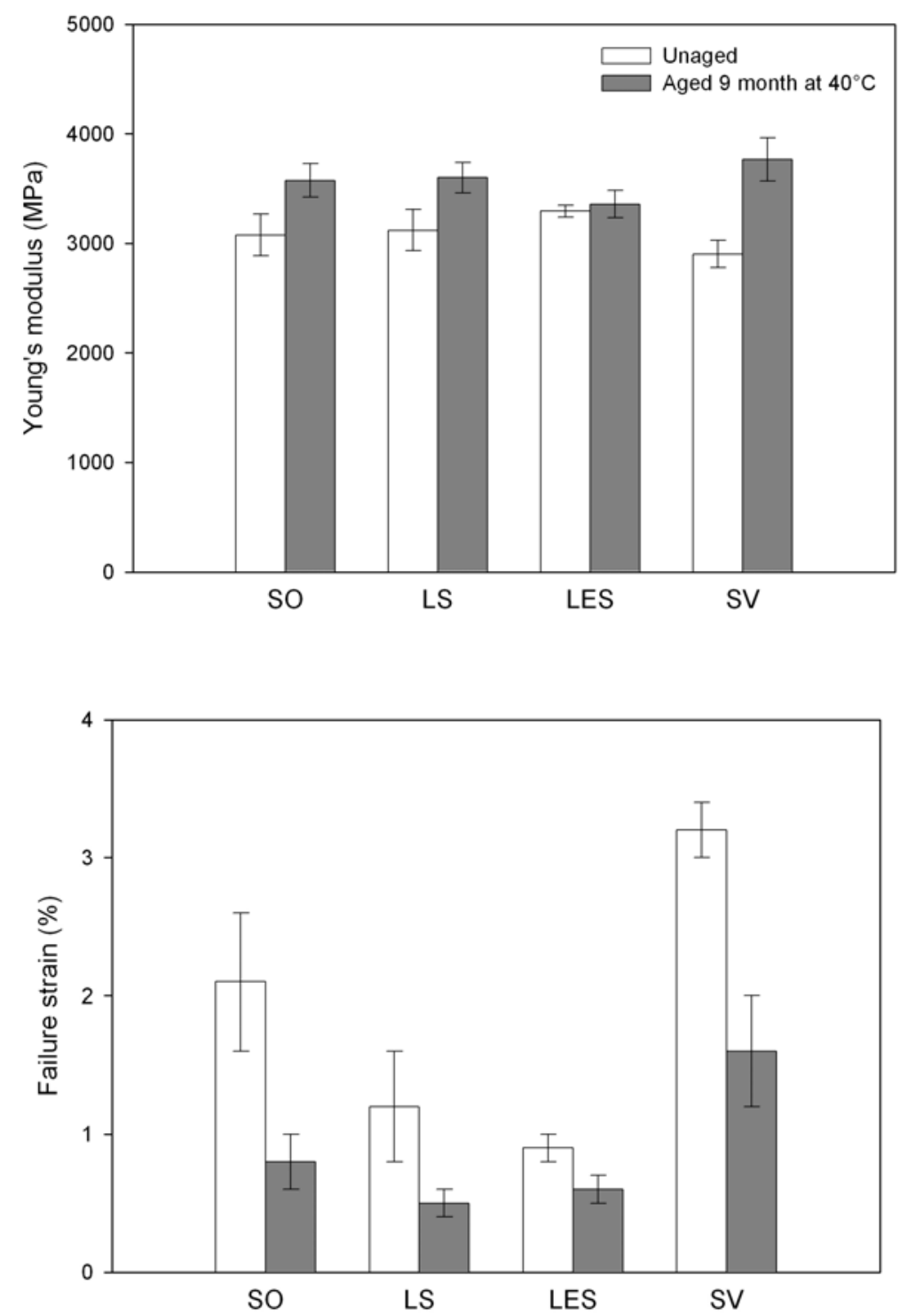

Figure 6 : Influence of 9 months' sea water ageing at $40^{\circ} \mathrm{C}$ on resin properties: Young's Modulus and failure strain. 

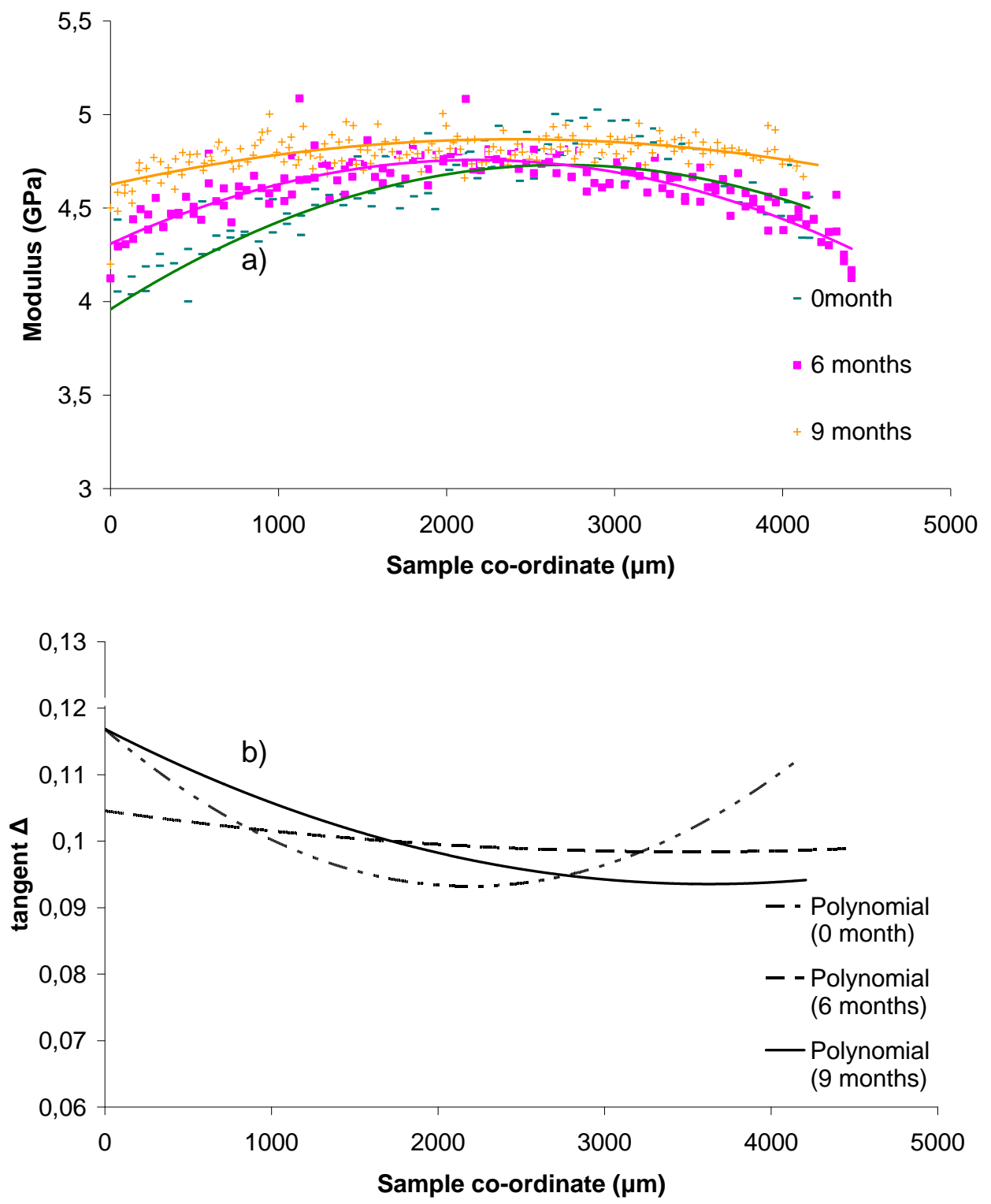

Figure 7 : Change in (a) modulus and (b) tangent $\delta$ through the thickness, with aging time, resin SO 


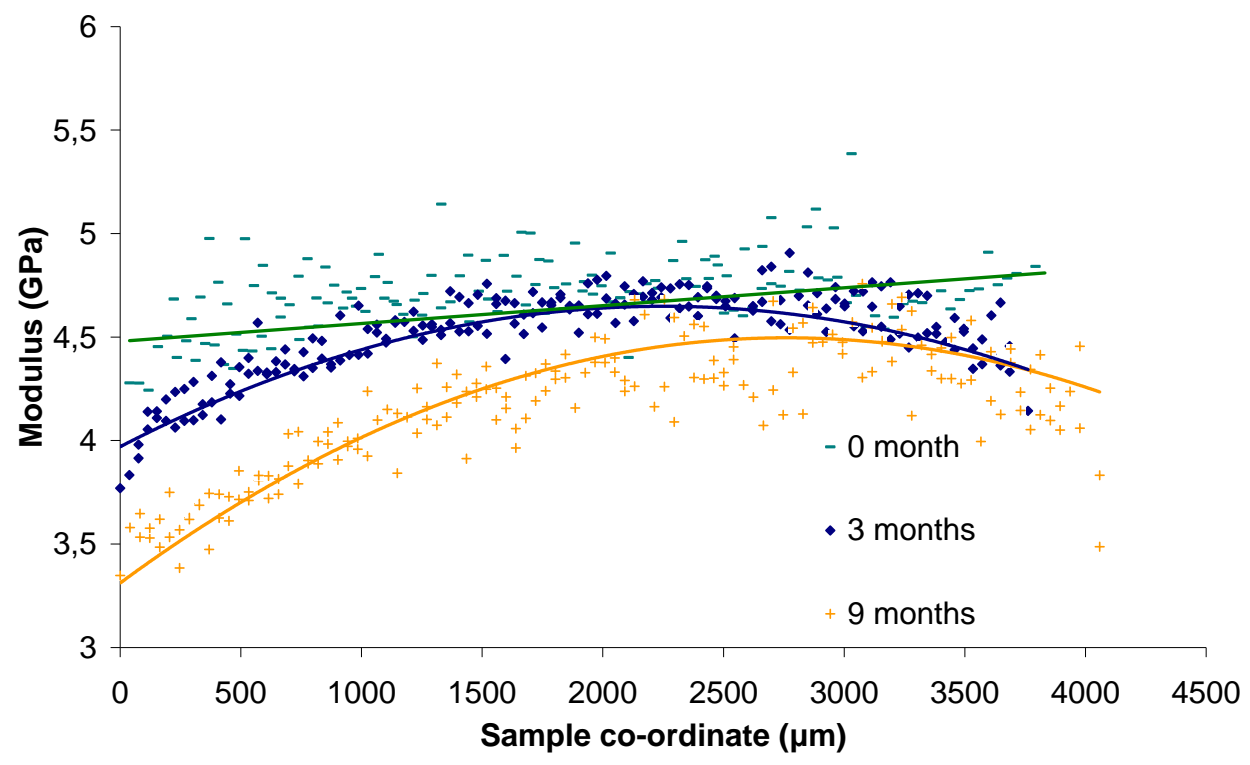

Figure 8: Change in modulus with aging time, resin LS.

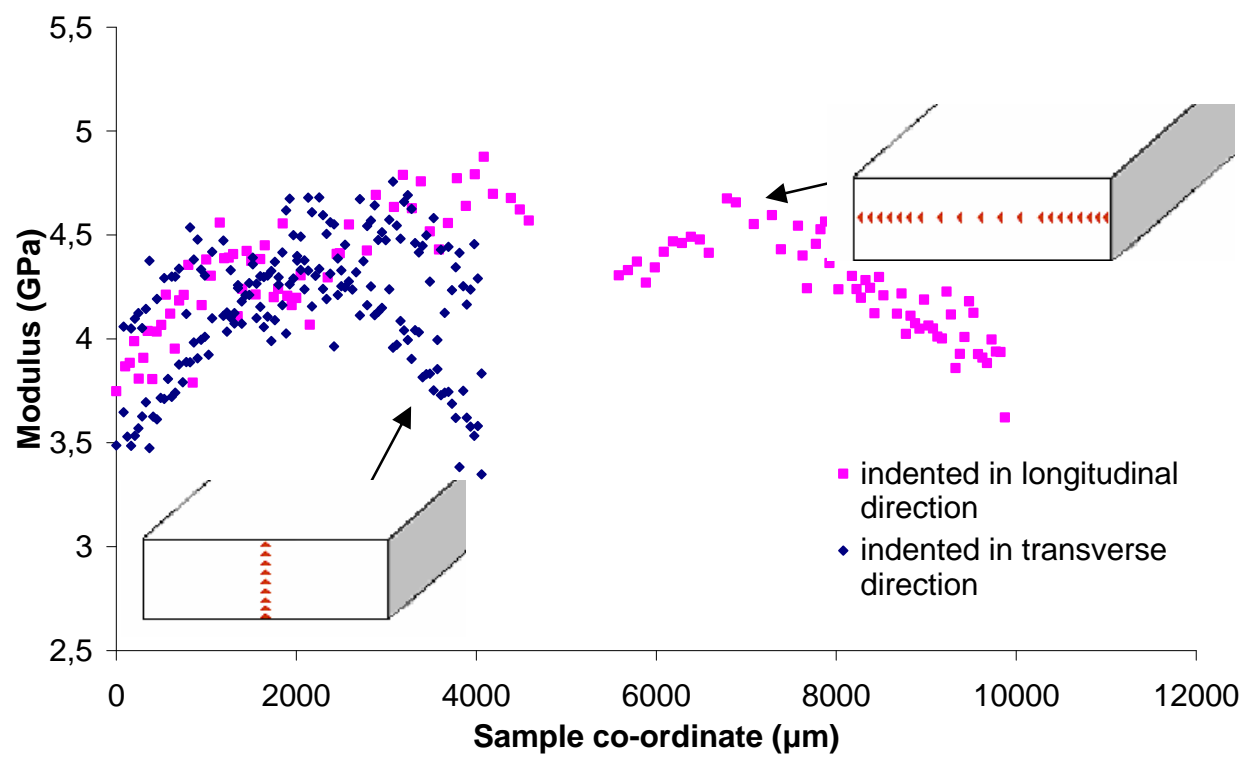

Figure 9: LS resin aged for 9 months, indented in transverse and longitudinal directions 

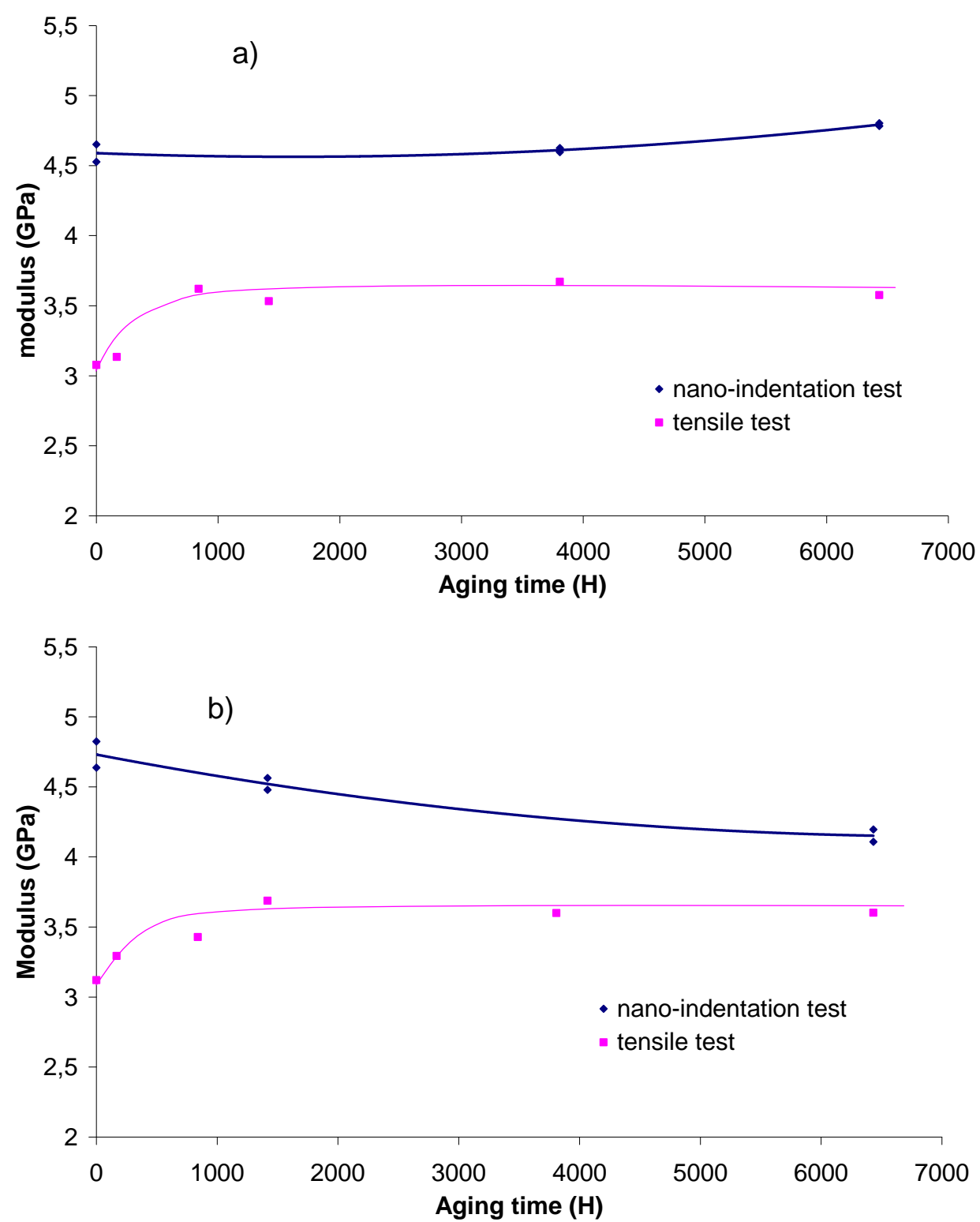

Figure 10: Comparison between tensile test modulus and averaged modulus values from nanoindentation a) SO (b) LS 


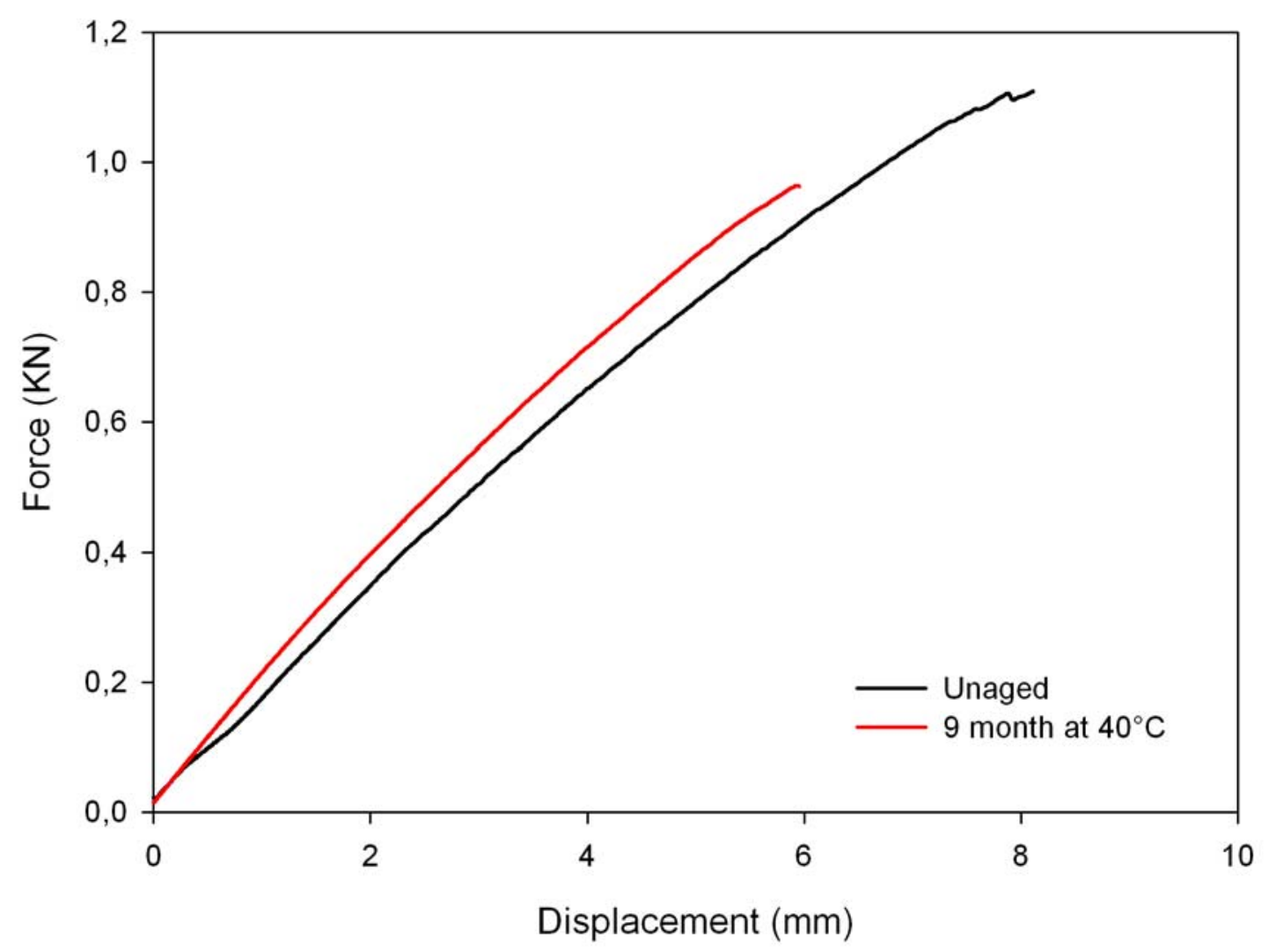

Figure 11. Typical load-displacement plots from flexural tests, LS composite. 

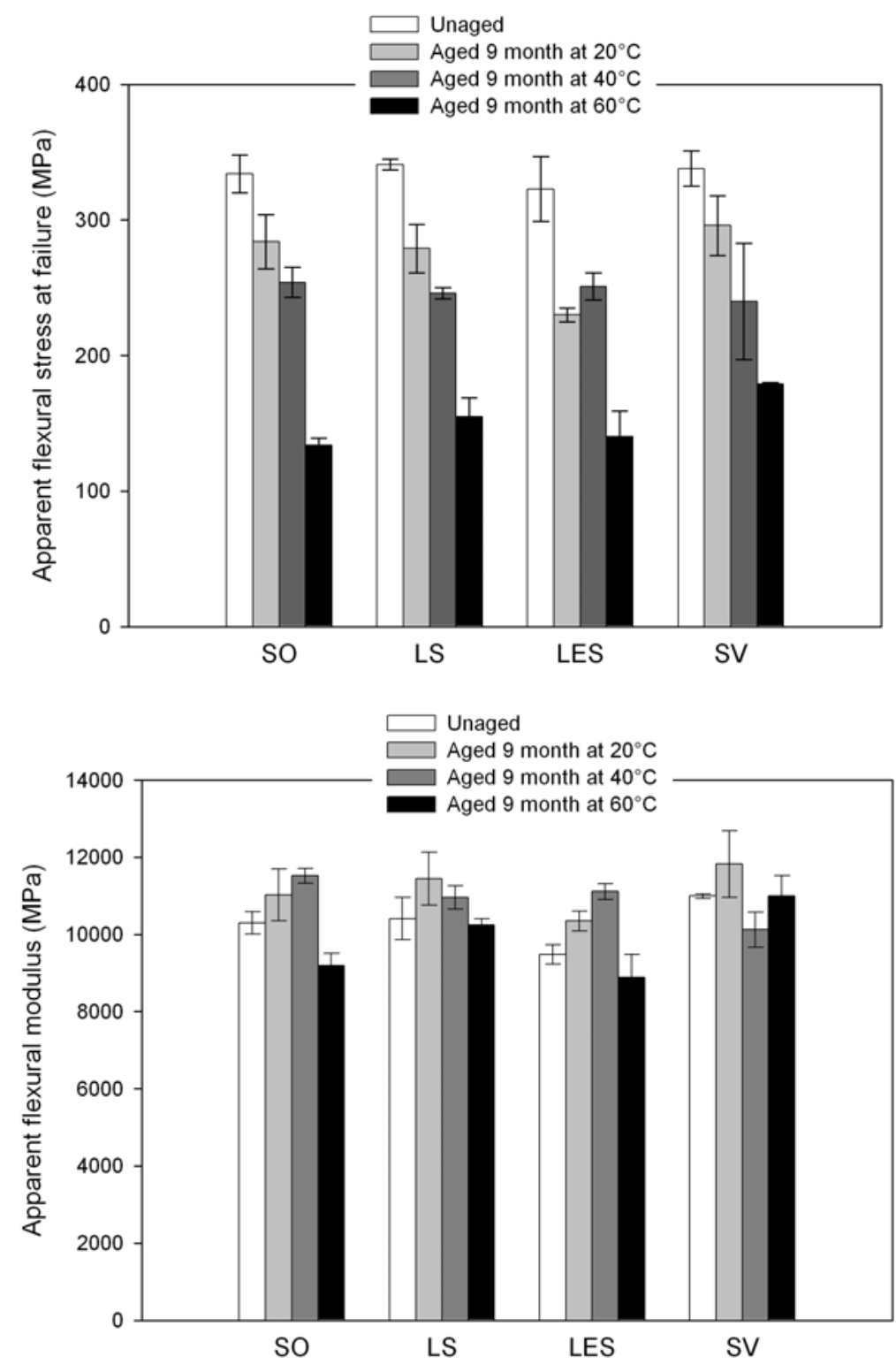

Figure 12: Influence of 9 months' sea water ageing at 20,40 and $60^{\circ} \mathrm{C}$ on flexural composites properties: Apparent modulus and stress at failure. 


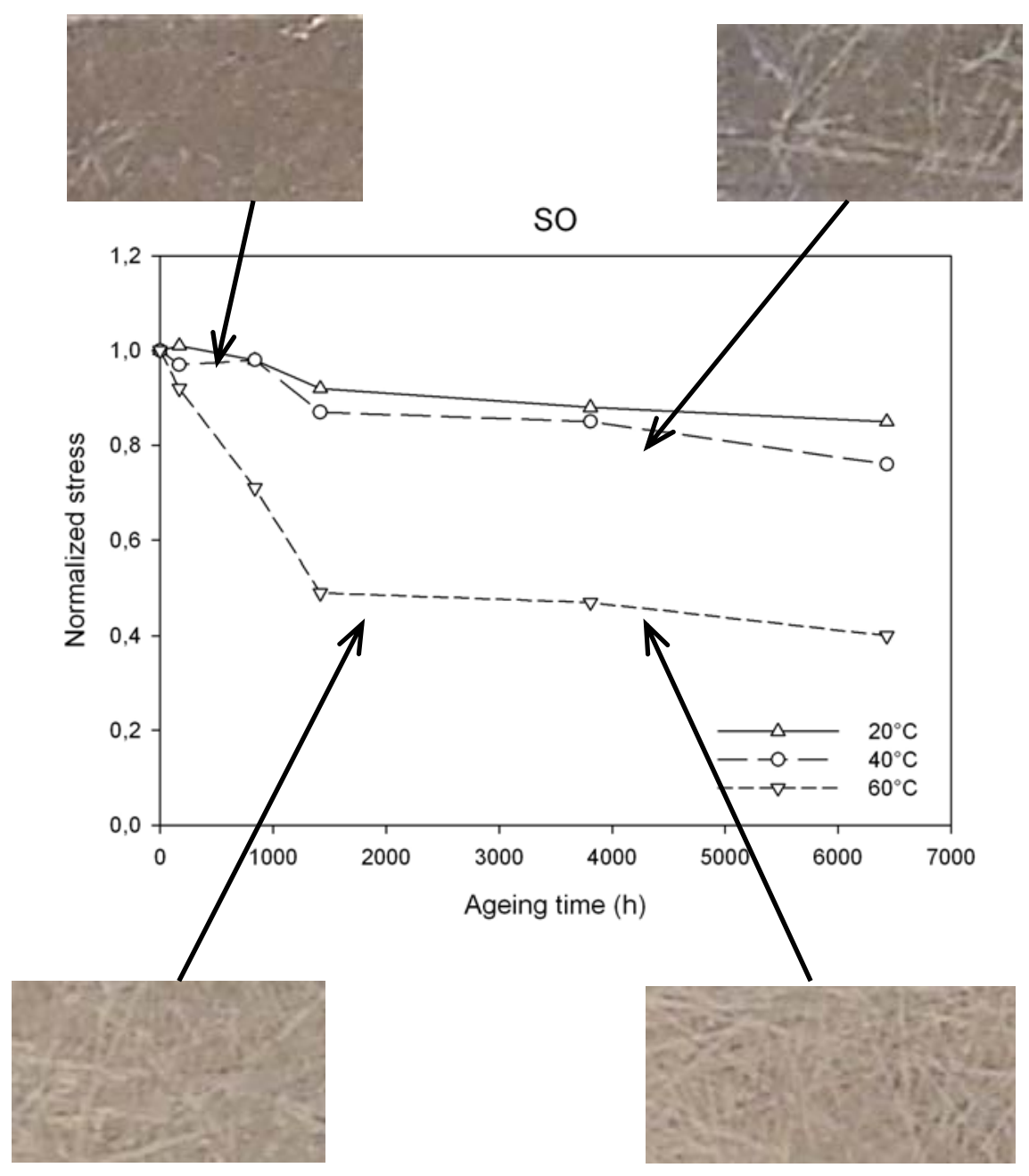

Figure 13: . Flexural strength of composite SO. Influence of ageing time and photos showing surface appearance. 


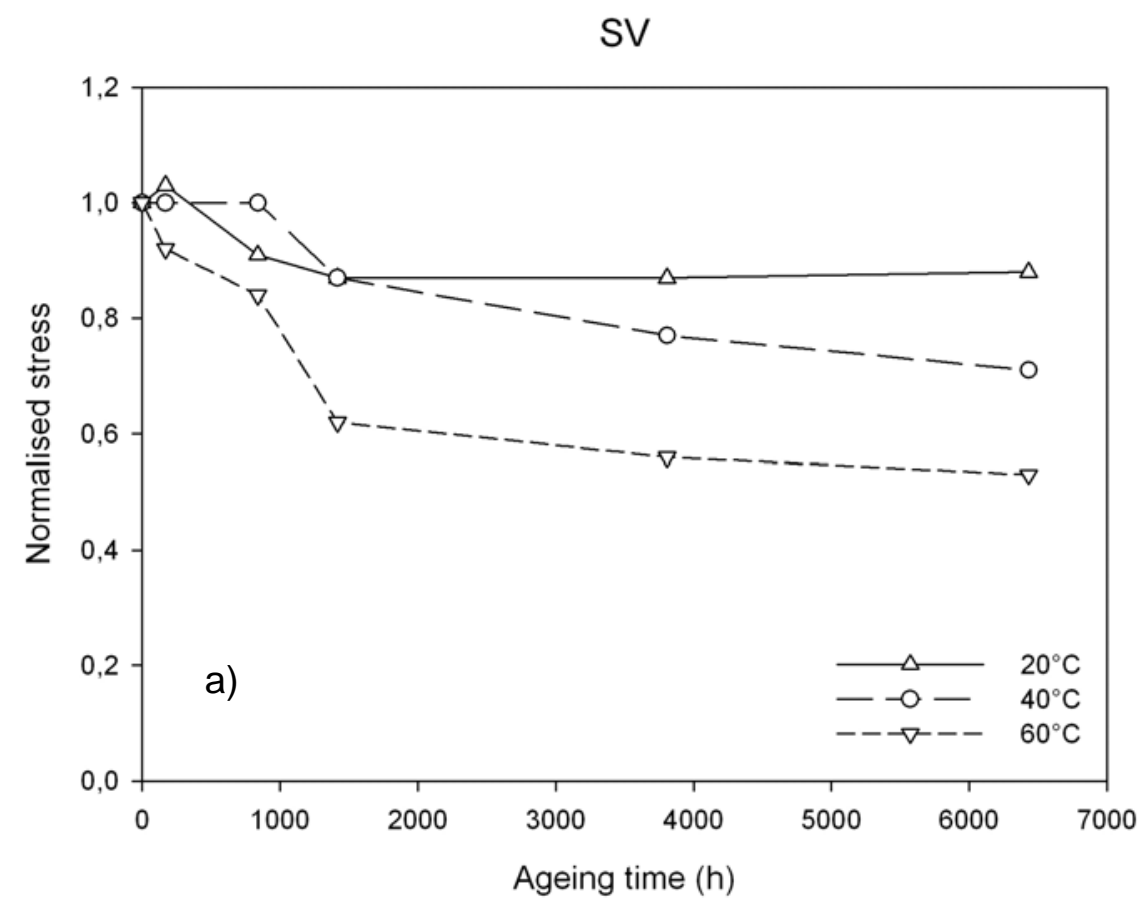

LS

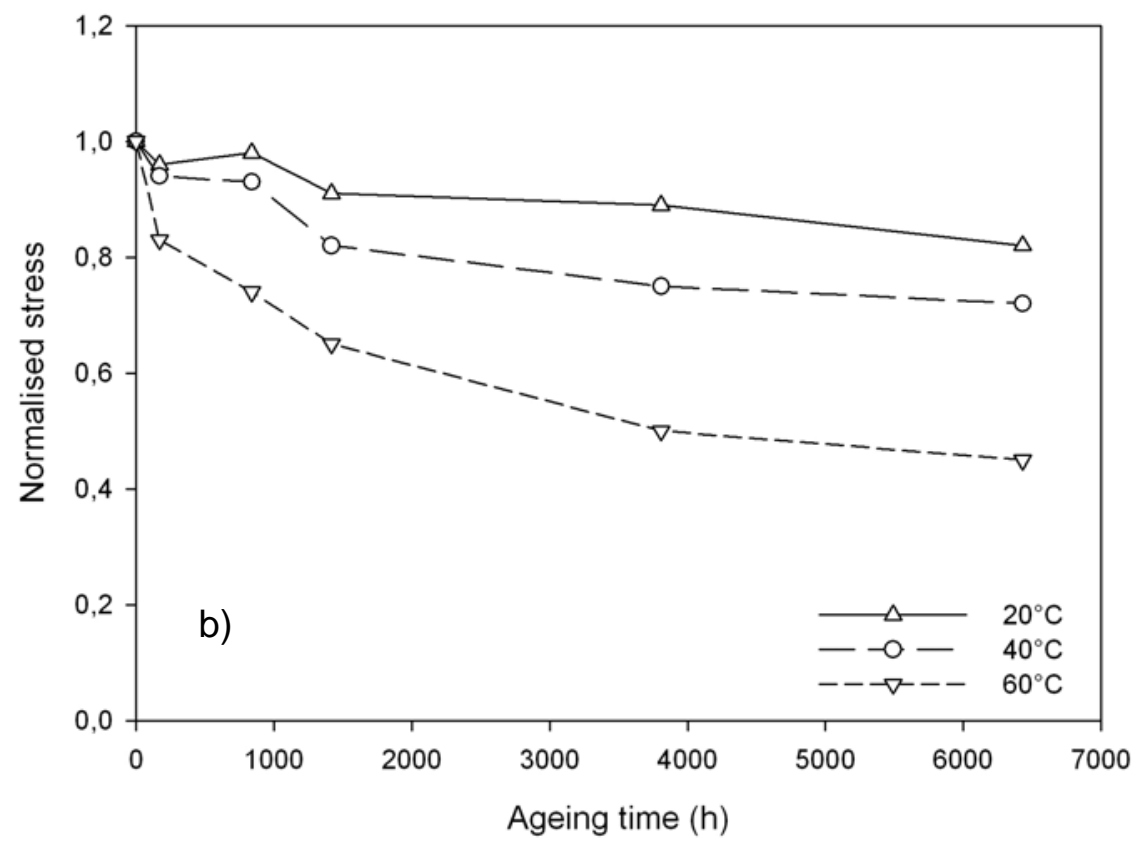

Figure 14: Ultimate flexural stress as a function of ageing time.

a) Composite SV, b) Composite LS. 
Tables

\begin{tabular}{ccccc}
\hline Resin & $\begin{array}{c}\text { Styrene content } \\
(\text { wt. \%) }\end{array}$ & $\begin{array}{c}\text { Young's } \\
\text { modulus (MPa) }\end{array}$ & $\begin{array}{c}\text { Failure stress } \\
(\mathrm{MPa})\end{array}$ & $\begin{array}{c}\text { Failure strain } \\
(\%)\end{array}$ \\
\hline SO & 42 & $3077 \pm 192$ & $49 \pm 7$ & $2.1 \pm 0.5$ \\
\hline LS & $35-38$ & $3120 \pm 188$ & $30 \pm 7$ & $1.2 \pm 0.4$ \\
\hline LES & $37-39$ & $3295 \pm 54$ & $25 \pm 3$ & $0.9 \pm 0.1$ \\
\hline SV & $48-51$ & $2901 \pm 125$ & $60 \pm 2$ & $3.2 \pm 0.2$ \\
\hline
\end{tabular}

Table 1: Initial resin properties [1] 


\begin{tabular}{cccc}
\hline & & $E$ & $E$ \\
Frequency, & Number of & Oliver-Pharr & Loubet \\
$\mathrm{Hz}$ & samples & {$[8]$} & {$[9]$} \\
& & $(\mathrm{GPa})$ & $(\mathrm{GPa})$ \\
\hline 10 & 42 & $5.198 \pm 0.319$ & $5.194 \pm 0.329$ \\
\hline 40 & 38 & $5.206 \pm 0.308$ & $5.176 \pm 0.316$ \\
\hline 70 & 41 & $5.081 \pm 0.273$ & $5.058 \pm 0.273$ \\
\hline 100 & 38 & $5.313 \pm 0.302$ & $5.296 \pm 0.327$ \\
\hline 120 & 38 & $5.068 \pm 0.341$ & $5.106 \pm 0.227$ \\
\hline 140 & 39 & $5.683 \pm 0.289$ & $5.704 \pm 0.287$ \\
\hline
\end{tabular}

Table 2: Influence of analysis method and frequency on nanoindentation modulus values, unaged standard polyester (SO) 


\begin{tabular}{ccccc}
\hline \multirow{2}{*}{ Reference } & \multicolumn{2}{c}{$\mathrm{E}^{\prime}$ at $30^{\circ} \mathrm{C}(\mathrm{GPa})$} & \multicolumn{2}{c}{$\mathrm{Tg}\left({ }^{\circ} \mathrm{C}\right)$} \\
\cline { 2 - 5 } & unaged & aged & unaged & aged \\
\hline SO & 3.5 & 3.8 & 58 & 73 \\
\hline LS & 3.9 & 4.1 & 58 & 78 \\
\hline LES & 3.5 & 3.6 & 58 & 78 \\
\hline
\end{tabular}

Table 3: DMA results for polyesters before and after 9 months in seawater at $40^{\circ} \mathrm{C}$. 